\title{
Repeated intra-articular injection of allogeneic mesenchymal stem cells causes an adverse response compared to autologous cells in the equine model
}

Amanda-Jo Joswig ${ }^{1}$, Alexis Mitchell ${ }^{1}$, Kevin J. Cummings ${ }^{2}$, Gwendolyn J. Levine ${ }^{3}$, Carl A. Gregory ${ }^{4}$, Roger Smith $\|^{3}$ and Ashlee E. Watts ${ }^{1 *}$

\begin{abstract}
Background: Intra-articular injection of mesenchymal stem cells (MSCs) is efficacious in osteoarthritis therapy. A direct comparison of the response of the synovial joint to intra-articular injection of autologous versus allogeneic MSCs has not been performed. The objective of this study was to assess the clinical response to repeated intraarticular injection of allogeneic versus autologous MSCs prepared in a way to minimize xeno-contaminants in a large animal model.

Methods: Intra-articular injections of bone marrow-derived, culture-expanded MSCs to a forelimb metacarpophalangeal joint were performed at week 0 and week 4 (six autologous; six autologous with xeno-contamination; six allogeneic). In the week following each injection, clinical and synovial cytology evaluations were performed.

Results: Following the first intra-articular injection, there were no differences in clinical parameters over time. Following the second intra-articular injection, there was a significant adverse response of the joint to allogeneic MSCs and autologous MSCs with xeno-contamination with elevated synovial total nucleated cell counts. There was also significantly increased pain from joints injected with autologous MSCs with xeno-contamination.
\end{abstract}

Conclusions: Repeated intra-articular injection of allogeneic MSCs results in an adverse clinical response, suggesting there is immune recognition of allogeneic MSCs upon a second exposure.

Keywords: MSC, Bone marrow, Serum-free, Horse, Joint, Flare, Intra-articular, Fetal calf serum, Fetal bovine serum, FBS

\section{Background}

The equine model is valuable for assessing stem cell therapies for musculoskeletal injury due to similarities in sport and age-related articular injuries that occur in people [1] and for the clinical experience of stem cell techniques in the horse for naturally occurring injury over the past several years [2]. Experimentally and clinically, intra-articular injection of autologous mesenchymal

\footnotetext{
*Correspondence: awatts@cvm.tamu.edu

'Department of Large Animal Clinical Sciences, Texas A\&M University, College Station, TX 77843, USA

Full list of author information is available at the end of the article
}

stem cells (MSCs) in the horse resulted in reduced pain and slowed osteoarthritis progression in an articular cartilage repair model [3] and clinical equine patients [4]. Positive effects of MSCs on osteoarthritis in the horse and other large animal models [5] have led to development of clinical trials in people utilizing both autologous and allogeneic MSCs for intra-articular injection [6-13].

Allogeneic MSCs would be advantageous to autologous MSCs for a number of reasons [14]. Since the first report of allogeneic MSCs in a clinical patient in 2004, allogeneic MSCs have been used in more registered clinical trials in the United States and undergone more 
published scientific reports than the use of autologous MSCs $[15,16]$. In contrast, for intra-articular application of MSCs in people, there have been more reports of autologous MSC use [6-11] and only one report on allogeneic MSCs [12]. To our knowledge, there have been no reports directly comparing the clinical response to intra-articular injection of autologous and allogeneic MSCs other than those in the equine model, where a lack of clinically relevant differences have been reported $[17,18]$. However, in each of these experimental reports, moderate to marked adverse clinical reaction with pain and joint effusion with cellular infiltrates were reported after a single intra-articular injection of autologous or allogeneic MSCs [17, 18]. Interestingly, when autologous and allogeneic chondroprogenitor cells were compared in the equine model there was reduced osteoarthritis progression when autologous cells were used but not allogeneic [19]. Because of the acute adverse reaction in these reports, we pose that the safety of allogeneic MSCs by intra-articular injection has not been fully investigated. Additionally, there are no reports on the response to repeated intra-articular injection of autologous or allogeneic MSCs in any species.

Safety of allogeneic MSC therapy by many routes of administration is relatively well-accepted. However, the articular environment is unique and considered to be particularly prone to immune reactions. First, the synovial joint is a confined space lined by synovial membrane that provides a blood-joint barrier [20-22]. As a result, large molecules such as proteins and cells do not equilibrate from the joint to the systemic circulation as rapidly as from most other tissues and organs. Second, the synovial membrane is composed of two major cell types: type A macrophage-like synoviocytes and type B fibroblast-like synoviocytes. The presence of type A, macrophage-like synoviocytes may lend the articular environment to enhanced immune responses and antigen recognition compared to other tissues [22].

Fetal bovine serum (FBS) is well recognized as a major safety concern prior to cell implantation in people because of development of antibodies to contaminating bovine proteins with subsequent rejection of cellular therapies [23-28]. Despite this, over half of reported MSC clinical trials utilize FBS during culture of MSCs [29]. This is because it is difficult to provide the necessary growth factors, hormones, vitamins, binding proteins, and other compounds that do not alter cellular behavior without FBS [29-31]. The reports that compared the articular reaction to autologous and allogeneic MSC injection in the equine model utilized FBS throughout their cellular propagation up to the time of intra-articular injection [17, 18].

We think the previously reported joint flare response to both autologous and allogeneic MSCs by intra-articular injection in the equine model could have been due to contaminating xeno-proteins $[17,18]$. If this adverse response was due to xeno-contaminants, differences in the articular joint response to autologous versus allogeneic MSCs could have been masked by the marked inflammatory reaction to xenogeneic protein. Thus, our objectives were twofold. First, we wanted to characterize the clinical joint response to repeated intra-articular MSC injection with a method to reduce the level of contaminating bovine proteins compared to FBS-containing methods. Second and more importantly, we wanted to characterize the clinical response of the equine synovial joint to repeated intra-articular injection of autologous and allogeneic MSCs, cultured in a manner to reduce contaminating bovine proteins. For the first objective, we demonstrated that intra-articular injection of autologous MSCs without efforts to minimize bovine protein contamination resulted in markedly increased adverse clinical reaction. For the second objective, when there is a reduction in contaminating bovine proteins by laboratory technique, the repeated intra-articular injection of allogeneic MSCs resulted in increased adverse clinical reaction compared to the injection of autologous MSCs, supporting the notion that there is an adaptive immune response of the synovial joint to intra-articular injection of allogeneic MSCs.

\section{Methods}

This study was approved by the university's Institutional Animal Care and Use Committee (IACUC protocol number 2013-097). No animals were euthanized for this study.

\section{Study design}

There were three groups of horses that received intraarticular injection of MSCs to a metacarpophalangeal joint: autologous cells depleted of FBS (AUTO; $n=6$ ), allogeneic cells depleted of FBS (ALLO; $n=6)$, and autologous cells not depleted of FBS (FBS; $n=6$ ). Mesenchymal stem cells from each AUTO horse were injected to one ALLO horse so there were six AUTO to ALLO pairs. The MSCs were prepared in vitro similar to previous reports $[17,18,32]$ with $\mathrm{FBS}$ in the media throughout the culture period. However, for FBS depletion in the AUTO and ALLO groups, FBS was removed from culture medium in the final 48 hours of MSC culture prior to intra-articular injection. The contralateral joint was injected with the same media used to suspend MSCs, alone (CONT).

Horses did not receive nonsteroidal anti-inflammatory medications and the limbs were not bandaged. Horses were housed individually in box stalls the week following intra-articular injection and serial clinical evaluations were performed. During the 3 weeks prior to the second intraarticular injection, horses were turned out to their normal group housing (field setting). Four weeks after the initial 
intra-articular injection, a repeat injection was performed and followed by the same post-injection evaluation.

\section{Animals}

Eighteen university-owned horses were used. All horses were female of the Quarter Horse breed and the age median age was 11.5 years (range 3-17; Additional file 1: Table S1). Within the ALLO group, one of the six mares had experienced a pregnancy prior to the study. Prior to inclusion in the study, horses were declared to be healthy based upon physical examination and did not have abnormalities related to the forelimb metacarpophalangeal joints as determined by normal range of motion, lack of joint effusion, and lack of response to joint flexion. Radiographic or other diagnostic imaging of the joints was not performed. Each horse was randomly assigned to a treatment group using an online program (http://www.random.org/). The treated forelimb was also randomly assigned by coin toss for each horse immediately prior to their initial intra-articular injection. The contralateral forelimb was used for CONT injection.

\section{MSC preparation}

Bone marrow was collected from the sternum for the isolation and expansion of MSCs from all six horses in the AUTO and FBS groups as previously described [33]. Bone marrow was not collected from the six horses in the ALLO group. In brief, after red blood cell lysis, bone marrow samples were resuspended in their original volume and plated at $30 \mathrm{~mL}$ original marrow volume/ $175 \mathrm{~cm}^{2}$ flask. At each passage MSCs were seeded at a density of $10,000 \mathrm{MSCs} / \mathrm{cm}^{2}$. Once MSCs were adequately expanded for all experiments and at approximately $60 \%$ of confluence in passage 3 or 4 , the MSCs intended for clinical injection in the AUTO and ALLO groups underwent FBS depletion. The final 48-hour treatment consisted of culture in complete medium supplemented with $10 \%$ autologous serum with the addition of ITS supplement (VWR, Radnor, PA, USA) (AUTO and ALLO) or continued growth in complete media with $10 \%$ FBS (FBS). The addition of ITS was performed because in previous experiments in our laboratory (data not shown) there was tremendous variability in MSC growth and metabolism when grown in autologous serum, which we presumed was due to differences in the quality of autologous serum. When we added ITS in pilot experiments to autologous serum supplemented MSCs, it allowed continued growth and metabolism, resulting in expulsion of intracellular FBS. Adherent MSCs were rinsed twice with $10 \mathrm{~mL}$ of Dulbecco's phosphate-buffered saline (DPBS) (Lonza, Walkersville, MD, USA) prior to the medium exchange and medium was replaced again after 24 hours of culture. Forty-eight hours after FBS depletion, adherent MSCs were collected by trypsinization (Corning,
Corning, NY, USA), rinsed by centrifugation and resuspension three times, and cryopreserved in 95\% autologous serum and 5\% dimethyl sulfoxide (DMSO) at a concentration of $10 \times 10^{6} \mathrm{MSC}$ per $\mathrm{mL}$.

\section{Assessment of FBS depletion}

Concurrent with cellular preparation for clinical injection, separate MSCs in the AUTO and FBS groups were used to assess FBS depletion. As previously described, FBS was covalently labeled with fluorescein isothiocyanate (FITC) [23]. The protein concentration used post FITC labeling was similar to the original FBS protein concentration and FITC-FBS was added to all complete media at $10 \%$. Media was exchanged for FITC-FBScontaining media in two culture flasks (per MSC donor) at a time point equivalent to 4 days prior to cryopreservation (at approximately 20-30\% confluence). After 2 days, one culture flask of the FITC-labeled MSCs had medium exchanged with FBS-free complete medium (supplemented with 10\% autologous serum and ITS) as described above for FBS depletion. The other FITC-FBS flask was maintained in fresh FITC-FBS for the final 48 hours of culture. MSCs from both flasks were then assessed for fluorescence intensity by flow cytometry (FACSCalibur, Becton Dickinson Immunocytometry Systems, San Jose, CA, USA), as a measure of remaining intra-cytoplasmic FITC-FBS. The population doubling time was calculated (days * $\log (2)) /(\log$ final concentration - log initial concentration).

\section{MSC characterization in vitro}

Immunophenotyping and trilineage differentiation was performed as previously described [33] on cells of the same passage and prepared in the same manner as those used for clinical injection. Briefly, dilutions of 1:100 for CD44 (Clone CVS18; Abcam, Cambridge, MA, USA), major histocompatibility complex class II (MHCII) (Clone CVS20; Abcam), CD29 (Clone 4B4-RD1; Beckman Coulter, Brea, CA, USA), 1:10 for CD45RB (Clone DH16A; VMRD, Inc., Pullman, WA, USA), and 1:400 for CD90 (Clone DH2A; VMRD, Inc.) were used. CD45RB and CD90 were stained with 1:100 secondary antibody (Jackson ImmunoResearch, West Grove, PA, USA). Immediately prior to analysis all cells were labeled with 7AAD (Biolegend, San Diego, CA, USA) to assess viability.

For chondrogenic differentiation, MSCs were grown in pellets of 500,000 cells for 21 days before being sectioned and stained with toluidine blue (Sigma-Aldrich, St. Louis, MO, USA). Cells were grown in Dulbecco's modified Eagle's medium $4.5 \mathrm{~g} / \mathrm{l}$ glucose supplemented with 1\% FBS, 2.5\% HEPES buffer, 10,000 units $/ \mathrm{mL}$ penicillin, $10,000 \mu \mathrm{g} / \mathrm{mL}$ streptomycin, $25 \mu \mathrm{g} / \mathrm{mL}$ amphotericin B, $0.2 \%$ transforming growth factor $\beta 3$ (Life Technologies, Grand Island, NY, USA), $301.89 \mu \mathrm{g}$ 
dexamethasone (Sigma-Aldrich), $50 \mu \mathrm{g} / \mathrm{mL}$ L-ascorbic acid (Sigma-Aldrich), $40 \mu \mathrm{g} / \mathrm{mL}$ proline (Sigma-Aldrich) and $1 \%$ ITS premix (VWR).

For osteogenic differentiation, MSCs were seeded to $10-\mathrm{cm}$ plates at 1000 cells per $\mathrm{cm}^{2}$ grown for 21 days with media exchanged three times weekly before staining with $2 \%$ alizarin red (Sigma-Aldrich). Osteogenic media contained Dulbecco's modified Eagle's medium F12 supplemented with $10 \%$ FBS, 10,000 units $/ \mathrm{mL}$ penicillin, $10,000 \mu \mathrm{g} / \mathrm{mL}$ streptomycin, $25 \mu \mathrm{g} / \mathrm{mL}$ amphotericin $\mathrm{B}$, $10 \mu \mathrm{M} / \mathrm{L}$ beta-glycerophosphate (Sigma-Aldrich), 20nM/ $\mathrm{L}$ dexamethasone, and $50 \mu \mathrm{g} / \mathrm{mL} \mathrm{L}$-ascorbic acid.

For adipogenic plates, MSCs were seeded to $10-\mathrm{cm}$ plates at 1000 cells per $\mathrm{cm}^{2}$ and grown for 6 days before fixing and staining with oil red $\mathrm{O}$ (Sigma-Aldrich). Adipogenic plates were maintained in Dulbecco's modified Eagle's medium F12 (VWR) supplemented with 3\% FBS, 10,000 units $/ \mathrm{mL}$ penicillin, $10,000 \mu \mathrm{g} / \mathrm{mL}$ streptomycin, $25 \mu \mathrm{g} / \mathrm{mL}$ amphotericin b, 5\% rabbit serum (Life Technologies), $33 \mu \mathrm{M} / \mathrm{L}$ biotin (Sigma-Aldrich), $17 \mu \mathrm{M} /$ L pantothenate (Sigma-Aldrich), $1 \mu \mathrm{M} / \mathrm{L}$ insulin (SigmaAldrich), $1 \mu \mathrm{M} / \mathrm{L}$ dexamethasone, $225 \mu \mathrm{L}$ isobutylmethylxanthine (Sigma-Aldrich), $89 \mu \mathrm{L}$ rosiglitazone (Sigma-Aldrich). After 3 days, media was then exchanged without the addition of isobutylmethylxanthine or rosiglitazone and maintained for another 3 days.

\section{Intra-articular MSC injection}

Horses were sedated with $0.4 \mathrm{mg} / \mathrm{kg}$ xylazine hydrochloride (Lloyd Inc., Shenandoah, IA, USA) $(100 \mathrm{mg} /$ $\mathrm{mL}$ ). The lateral aspect of each metacarpophalangeal joint was aseptically prepared. Immediately prior to joint injection, vials containing MSCs (AUTO, ALLO or FBS previously frozen in $95 \%$ autologous serum and 5\% DMSO) or media alone (the same media composition used for MSCs) were thawed in a $37{ }^{\circ} \mathrm{C}$ water bath. A 20-gauge, 1-inch needle was inserted into the joint distal to the lateral collateral sesamoidean ligament and $2 \mathrm{~mL}$ of synovial fluid was collected and transferred to tubes containing EDTA for cytological analysis. Following synovial fluid collection, MSC or CONT injection was performed as appropriate for each joint. Control joints were injected with $1 \mathrm{~mL}$ of $95 \%$ autologous serum and 5\% DMSO and MSC joints were injected with approximately 10 million MSCs suspended in $1 \mathrm{~mL}$ of $95 \%$ autologous serum and 5\% DMSO.

\section{Serial evaluations - synovial cytology}

On the day of injection (day 0 and day 29) and on days 1, 2, 3, and 7 (and 30, 31, 32, and 36) after injection, cytological evaluation of synovial fluid was performed on all cell-injected and control joints. Synovial fluid cytological evaluation was performed in control joints on days 0 and 1 , and days 29 and 30. Collection of synovial fluid was performed as described above for the MSC injections. Evaluations included total protein concentration via refractometry, total nucleated cell count, and total nucleated cell differential, and a cytological evaluation by a board-certified veterinary clinical pathologist.

\section{Serial evaluations - clinical evaluation}

Horses were monitored by routine physical examination and assessed for lameness at a walk every 12 hours for the week following each intra-articular injection. If any horse had lameness visible at a walk for $\geq 24$ hours, rescue analgesia was administered $(4.4 \mathrm{mg} / \mathrm{kg}$ phenylbutazone, intravenously (IV) every 24 hours) until lameness was no longer visible at a walk. Assessment of lameness was done with an objective inertial sensor system (Lameness Locator ${ }^{\circ}$ ) as previously described [34, 35] on the same days and immediately prior to synovial fluid collection from injected joints.

\section{Statistical analysis}

Data were imported into a commercial statistical software program (SAS, version 9.4; SAS Institute Inc., Cary, NC, USA) for analysis. Repeated measures analysis of variance (ANOVA) was used to compare temporal changes in the cytologic and clinical outcome variables for each pair of treatment groups, with horse considered a random effect. These analyses were performed using PROC MIXED, and an autoregressive correlation structure was specified. Treatment group, time point, and their interaction were included as factors in the ANOVA. The Wilcoxon rank-sum test was used to compare population doubling time between the autologous serum-treated MSCs and the FBS-treated MSCs. For all analyses, $p$ values $<0.05$ were considered significant.

\section{Results}

Bone marrow-derived MSCs were successfully isolated and expanded from all horses in the AUTO and FBS groups. All joint injections and follow-up procedures went well, and no horse had any adverse event that required cessation of the study or unplanned procedures or treatments. No horses had abnormalities identified on twice daily physical examinations in the week following each intra-articular injection. Although two horses had lameness at a walk 8 hours after intra-articular injection (one after the initial injection in the control limb of the FBS group and one after the repeated injection in the cell-treated limb of the ALLO group), this was resolved by 24 hours and therefore no horses required rescue analgesic medication. The median age was 11.5 years (range 3-17; Additional file 1: Table S1) and all were female.

The population doubling time for MSCs prepared for clinical injection was not different between the autologous 
serum-prepared MSCs $(2.5,2.3-4.1$; median, IQR) and the FBS-prepared MSCs $(2.4,1.8-3.2$; median, IQR). Cell viability was $70 \%$; $\pm 15 \%$ (mean; standard deviation) after the initial injection and $85 \% ; \pm 7 \%$ after the second injection.

\section{FBS depletion}

All MSC cultures grown with FITC-FBS were visibly fluorescent under UV light. After removal of FITC-FBS complete media, intra-cytoplasmic fluorescence could be detected under UV light (Additional file 2: Figure S1A). After 48 hours of culture in autologous supplemented complete media there was little remaining intracytoplasmic fluorescence for MSCs from all horses (Additional file 2: Figure S1B). Flow cytometry revealed that the mean fluorescence intensity (MFI) of cell cultures without FBS was reduced by a greater than 95\% compared to that of cells maintained in FITC-FBS (Additional file 2: Figure S1C). The population doubling time during the FBS depletion period was not different $(p=0.15)$ between the autologous serum-treated MSCs (2.9, 1.5-6.0; median, IQR) and the FITC-FBS-treated MSCs (2.1, 1.5-4.0; median, IQR).

\section{MSC characterization in vitro}

All MSCs were positive for CD90 and CD29, and negative for CD45; three horses were positive for CD44 and the remaining nine were negative; and two horses were positive for MHCII and the remaining ten were negative (Table 1; Additional file 3: Figure S2). All MSCs were positive for trilineage differentiation after osteogenic, chondrogenic, and adipogenic differentiation (Additional file 4: Figure S3).

Table 1 Cell surface markers of MSCs

\begin{tabular}{lllllll}
\hline Horse \# & Group & MHCII & CD44 & CD29 & CD45 & CD90 \\
\hline 1 & FBS & + & - & + & - & + \\
2 & AUTO/ALLO & + & - & + & - & + \\
3 & FBS & - & + & + & - & + \\
4 & AUTO/ALLO & - & - & + & - & + \\
5 & AUTO/ALLO & - & - & + & - & + \\
6 & FBS & - & - & + & - & + \\
7 & FBS & - & - & + & - & + \\
8 & AUTO./ALLO & - & - & + & - & + \\
9 & FBS & - & - & + & - & + \\
10 & AUTO/ALLO & - & + & + & - & + \\
11 & FBS & - & - & + & - & + \\
12 & AUTO/ALLO & - & + & + & - & + \\
\hline
\end{tabular}

MSCs mesenchymal stem cells, MHCII major histocompatibility complex class II, FBS autologous cells not depleted of fetal bovine serum (FBS), AUTO autologous cells depleted of FBS, ALLO allogeneic cells depleted of FBS

\section{Synovial cytology}

Following the first joint injection, the change in total nucleated cell count (TNCC) over time was not significantly different between either the AUTO and FBS groups or the AUTO and ALLO groups. Following the second joint injection 4 weeks later, there was a significant difference in the TNCC over time between the AUTO and FBS groups ( $p=0.03$; FBS was higher) and the AUTO and ALLO groups $(p=0.009$; ALLO was higher). Specifically, there was a significant group effect at day 30 for the AUTO and FBS groups $(p=0.0007$; FBS was higher) and the AUTO and ALLO groups ( $p=$ 0.0009; ALLO was higher). Other cytology parameters did not differ significantly over time between groups after the first or second intra-injection (Fig. 1). The modest changes in percentage of neutrophils and total protein were similar to those from control injected articular joints, which did not vary with time (Additional file 5: Figure S4).

There were MSCs from two horses that expressed MHCII molecules: one was in the FBS group and the horse received its own MSCs and the other was in the ALLO group. Horse 14 in the ALLO group received MHCII-positive cells from horse 2 . The day after the initial cell injection, horse 14 's TNCC $(14,841$ cells $/ \mu \mathrm{L}$; ALLO median of 11,025 cells $/ \mu \mathrm{L}), \mathrm{TP}(0.1 \mathrm{~g} / \mathrm{dL}$; ALLO median of $2.2 \mathrm{~g} / \mathrm{dL}$ ) and percentage of neutrophils (54\%; ALLO median of 55\%) were similar to the ALLO group medians. The day after the second intra-articular cell injection, horse 14's TNCC $(19,674$ cells $/ \mu \mathrm{L}$; ALLO median of 19,234 cells $/ \mu \mathrm{L})$ and TP $(2.4 \mathrm{~g} / \mathrm{dL}$; ALLO median of $2.55 \mathrm{~g} / \mathrm{dL}$ ) were similar to the group median. However the percentage of neutrophils was the highest of the group at $75 \%$ (ALLO group median of $52 \%$ ).

One mare within the ALLO group, horse 17, had experienced a pregnancy prior to the study. The day after the initial cell injection, horse 17's TNCC (18,360 cells/ $\mu \mathrm{L}$; ALLO median of 11,025 cells $/ \mu \mathrm{L}$ ) was slightly higher than the group median. The day after the second cell injection, horse 17's TNCC (17,472 cells/ $\mu \mathrm{L}$; ALLO median of 19,234 cells $/ \mu \mathrm{L}$ ) was slightly lower than the group median.

\section{Clinical evaluation}

Lameness was evident at a walk in two horses the day of intra-articular MSC injection, but was resolved within 24 hours. Therefore no horses required rescue analgesia.

After the first injection, there was a marginal difference in the Lameness Locator ${ }^{\bullet}$ evaluation over time between the AUTO and FBS groups $(p=0.06)$ but not between the AUTO and ALLO groups $(p=0.2)$. After the second injection, there was a significant difference between the AUTO and FBS groups ( $p=0.046$; FBS had increased lameness) and a marginal difference between 

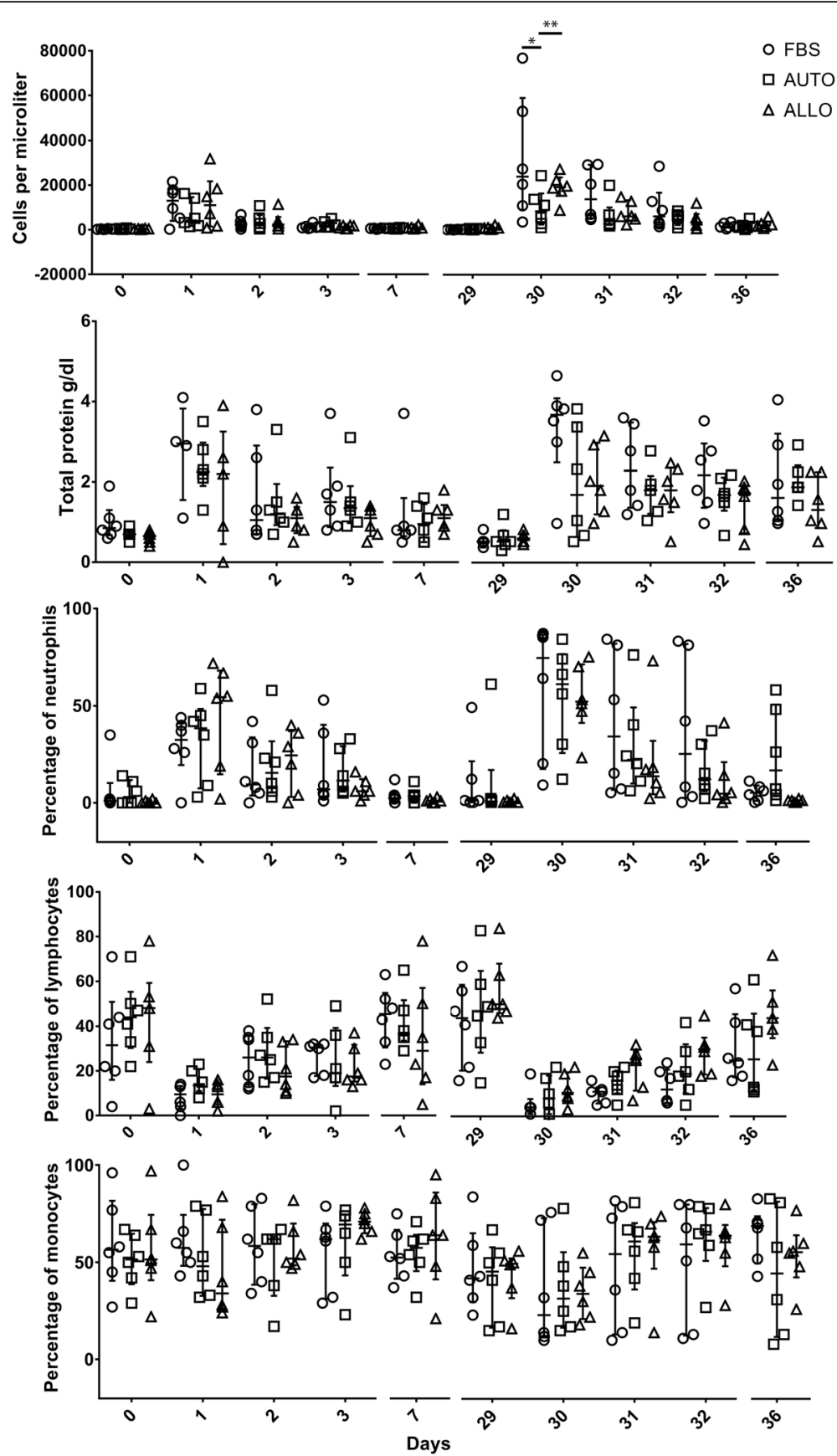

Fig. 1 Synovial fluid cytology box plots of total nucleated cell count (TNCC), percentage of neutrophils (PMN), total protein concentration (TP), percentage of lymphocytes and percentage of monocytes. Repeated measures analysis of variance (ANOVA) was used to compare temporal changes in the cytologic outcome variables for each pair of treatment groups (AUTO to FBS and AUTO to ALLO), with horse considered a random effect. These analyses were performed using PROC MIXED, and an autoregressive correlation structure was specified. Treatment group (AUTO, ALLO or FBS), time point, and their interaction were included as factors in the ANOVA. Following the first intra-articular MSC injection, the change in total nucleated cell count (TNCC) over time was not significantly different between either the AUTO and FBS groups or the AUTO and ALLO groups. Following the second joint injection 4 weeks later, there was a significant difference in the TNCC over time between the AUTO and FBS groups ( $p=0.03$; FBS was higher) and the AUTO and ALLO groups ( $p=0.009$; ALLO was higher). Specifically, there was a treatment effect at day 30 for the AUTO and FBS groups ( $p=0.0007$; FBS was higher) and the AUTO and ALLO groups ( $p=0.0009$; ALLO was higher). Other cytology parameters did not vary over time for either group after either injection. FBS autologous cells not depleted of fetal bovine serum (FBS), AUTO autologous cells depleted of FBS, ALLO allogeneic cells 
the AUTO and ALLO groups ( $p=0.09$; ALLO had increased lameness). There was a significant group effect at day 30 between the AUTO and FBS groups ( $p=$ 0.0006; FBS had increased lameness) (Fig. 2).

\section{Discussion}

In this manuscript, there are three main findings. First, laboratory technique to remove xeno-contaminants arising from fetal bovine serum prior to injection of MSCs has a profound effect on the clinical reaction of the synovial joint after intra-articular MSC injection. Using fluorescent microscopy and flow cytometry we demonstrated a greater than $95 \%$ reduction in intracellular FITC-FBS after a 48-hour FBS depletion culture period. Xeno-contamination of MSCs when FBS depletion was not performed resulted in marked adverse clinical reaction to a single and repeated intra-articular injection of autologous MSCs compared to autologous MSCs that were FBS-depleted. Second, in strong contrast to previous reports $[17,18]$ a single intra-articular injection of autologous MSCs did not result in an adverse clinical reaction and there were no increases in TNCC, joint effusion or pain $[17,18]$. The third and foremost finding was that repeated intra-articular injection of allogeneic MSCs resulted in adverse clinical reaction after a second injection, 4 weeks later. The increased adverse reaction was characterized by a trend of increased lameness and significantly increased synovial cellular infiltrates compared to autologous MSCs by repeated intra-articular injection. Given the increased adverse clinical reaction after the second intra-articular injection of allogeneic MSCs, it is likely that the reaction is due to adaptive immune activation by allogeneic MSCs but not autologous MSCs.
Control joints injected with media alone $(95 \%$ autologous serum and 5\% DMSO that had been thawed immediately prior to injection) were used to assess for a response to synoviocentesis and media itself. In cell-injected joints, there were mild increases in the percentage of neutrophils and total protein after the initial MSC injection in all three groups. These values were further increased after the second injection, again for all three groups. Because similar changes were seen in the control injected joints, this is simply a response of the synovial joint to synoviocentesis and to the control media itself. The elevations in neutrophils and total protein and lack of elevation in TNCC from our control injected joints were less than that reported after intra-articular saline injection, which causes a mild and transient synovitis [36].

Immune responses to allograft can occur via several pathways involving both innate and adaptive immunity. Although the immune privilege and immune modulatory activity of allogeneic MSCs in vitro is fairly well understood and frequently cited, allogeneic MSCs are now being considered immune-evasive in vivo rather than truly immune privileged [16]. This is because of the reduced long-term persistence of allogeneic MSCs [37-42], increased allo-antibody production [43, 44], increased cellular infiltrates [37-39, 45], and complete immune responses (cellular and humoral) [46, 47] that occur after allogenic MSC administration compared to autologous. Thus, immune responses to allogeneic MSCs secondary to their immunogenicity could negatively impact cellular longevity and efficacy $[16,48,49]$.

The expression of MHCII by equine MSCs has been reported to be variable [50] despite maintaining the expected immunophenotype for MSCs and expected ability

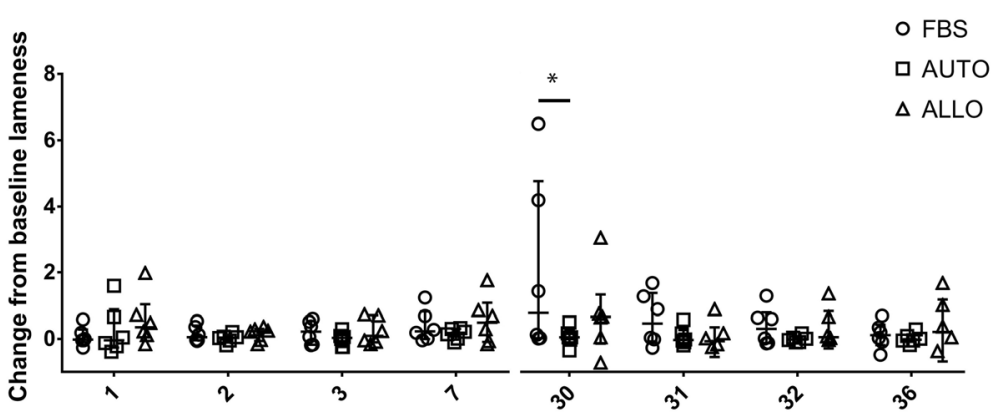

Fig. 2 Box plot of the change of Lameness Locator ${ }^{\circledR}$ scores compared to the baseline examination at day 0 and 29. Repeated measures analysis of variance (ANOVA) was used to compare temporal changes in the change of lameness from baseline for each pair of treatment groups (AUTO to FBS and AUTO to ALLO), with horse considered a random effect. These analyses were performed using PROC MIXED, and an autoregressive correlation structure was specified. Treatment group (AUTO, ALLO or FBS), time point, and their interaction were included as factors in the ANOVA. After the first injection, there was a marginal difference in the Lameness Locator ${ }^{\oplus}$ evaluation over time between the AUTO and FBS groups ( $p=0.06$; FBS had increased lameness) but not between the AUTO and ALLO groups ( $p=0.2)$. After the second injection, there were significant differences between the AUTO and FBS groups ( $p=0.046$; FBS had increased lameness) and a marginal difference between the AUTO and ALLO groups ( $p=0.09$; ALLO had increased lameness). There was a significant treatment effect at day 30 between the AUTO and FBS groups ( $p=0.0006$; FBS had increased lameness). FBS autologous cells not depleted of fetal bovine serum (FBS), AUTO autologous cells depleted of FBS, ALLO allogeneic cells depleted of FBS 
to undergo trilineage differentiation. One horse in this study within the ALLO group received MSCs that were MHCII positive. This did not influence the adverse joint reaction and the values of TNCC and TP from the individual horse were similar to the ALLO group medians, which indicate that $\mathrm{T}$ cell responses are not responsible for the adverse clinical response or that the AUTO ALLO paired was MHC compatible. Thus it is more likely that MHCI or other cell surface molecules are responsible for the apparent immunogenicity of allogeneic MSCs that we demonstrate.

Pregnancy can prime a mother against the foreign MHC haplotype(s) of her offspring's father, and all animals in this study were female [51]. Within the allogeneic group, only one horse had experienced a pregnancy. The synovial TNCCs the day following the initial and primed injections from this horse were similar to the ALLO group medians and not different to each other, suggesting that the allogeneic MSCs she received were either of a different MHC haplotype than the sire of her foal, or that she did not mount a primed immune response for another reason, including the possibility that she might have shared the same MHC haplotype as the sire of her foal. Nevertheless, it is important to recognize the importance of the chance for priming against $\mathrm{MHC}$ molecules in females that have been pregnant and will receive allogeneic cells.

Despite recognition of potential problems associated with xeno-contaminants in MSCs [23, 29-31, 52] FBS was used throughout the MSC isolation and propagation in each of the previously reported experimental studies evaluating intra-articular MSC injection in the equine model $[17,18,53]$. In the report herein, FBS was utilized until the final 48 hours of the culture period where FBS was replaced with autologous serum to minimize the immunogenicity of xenocontamination of MSCs. This FBS depletion protocol resulted in a greater than 95\% reduction in the amount of contaminating intracellular bovine proteins and a concomitant reduction in adverse inflammatory reaction to autologous MSCs following repeated intraarticular injection.

Since there was incomplete removal of FBS, differences in MSC growth rate or metabolism could have led to small individual differences in the clearance of intracellular FBS during the 48-hour FBS depletion period. Given the marked response of the synovial joint to FBScontaminated MSCs, it is possible the minor differences in the level of xeno-contaminants could cause major changes in recipient immune reaction. The use of autologous and allogenic matched pairs controlled for this possibility because each group (AUTO and ALLO) would have received the same amount of persisting xeno-contaminant.
We expected there would be a marked adverse response of the joint after intra-articular injection of MSCs prepared with xeno-contamination (FBS group), similar to that reported previously $[17,18]$. A surprising finding was that even from this group, the post-injection TNCC after the initial injection was very low (approximately 1 / 3 to $1 / 5$ ) compared to previous reports. This was despite intra-articular injection with a similar number of autologous bone marrow-derived MSCs [17, 18]. Reduced adverse reaction to the initial MSC injection contaminated with FBS reported herein could be due to differences in laboratory preparation techniques [54]. The MSCs of this report were cryopreserved until immediately prior to intra-articular injection, which is in contrast to the prior reports where fresh MSCs were utilized [17, 18]. Interestingly, our synovial TNCC was comparable to that reported by Williams et al., who tested cryopreserved allogeneic cord blood-derived MSCs for intraarticular injection in the equine model [53]. It is possible that cryopreservation somehow selects for or signals MSCs to be "better" [33, 55]. Interestingly, cryopreservation may also impair the immunomodulatory properties of MSCs [56]. Certainly in our experiment after the initial injection, if cryopreservation had an effect, it appeared to be one of improved immunomodulatory properties because of lack of adverse clinical reaction in all groups after the initial MSC injection.

In addition to a possible effect on the cells by the cryopreservation and thawing process, cryopreservation media components themselves (DMSO or serum) may also be protective against an adverse inflammatory reaction in the synovial environment as both DMSO and serum are known to be anti-inflammatory $[57,58]$. However, all injected joints received the same amount of DMSO and autologous serum, so if there was an effect, it would have reduced the adverse clinical reaction in all groups. Certainly, the anti-inflammatory effects of media were not enough to abolish the increased adverse clinical reaction in the ALLO and FBS groups. Finally, the amount of DMSO was $50 \mu \mathrm{L}$ per joint, which is a very small dose for an equine metacarpophalangeal joint that has a joint volume of approximately $12.5 \mathrm{~mL}$ [59].

Cell viability at the time of intra-articular injection could affect the host response. After the initial injections, cell viabilities were lower than expected (70\%) based on previous experience [60]. This is because the animal site was distant to the laboratory causing a significant lag between thawing and testing of cell viability. At the second intra-articular injection extra effort was made to transport the tubes and test the viability as quickly as possible. Unfortunately, there was still a time delay of 1-2 hours and viability (85\%) remained lower than expected based on previous experience [60]. Thus, the viabilities reported herein do not reflect MSC 
viability at the time of injection or even 1-2 hours following injection in vivo. This is because of the very different environment of the synovial joint as compared to an undiluted laboratory vial. Thus no attempts were made to compare the adverse clinical reaction to postthaw MSC viability.

Another MSC factor that could affect the synovial response to MSCs is the metabolic activity of the cells at the time of intra-articular injection. Population doubling times were calculated as a measure of metabolic rate and there were no differences between the groups. Therefore, differences in MSC growth should have affected all three groups equally. However, if there were differences in the metabolic rate of injected MSCs within each group, we expected that injection of MSCs containing FBS contamination would have the greatest effect on clinical response. This is because very metabolically active MSCs would release FBS to the synovial environment at a faster rate than a senescent cell. We found the widest variability in adverse clinical reaction in the FBS group after the second intra-articular injection, and the two horses with the lowest population doubling times (most metabolically active) had the highest total nucleated cell counts in that group. This is indirect evidence that differences in the metabolic rate of MSCs resulted in variability in the exposure of the intra-articular environment to xeno-antigens and the resultant host response. Certainly, future studies should report the growth rate of MSCs immediately prior to treatment injection as it may affect host response and cellular efficacy.

A limitation of this study is that all joints were normal and it is possible that there would be a different response of the inflamed or osteoarthritic synovial joint to allogeneic MSCs or MSCs contaminated with FBS. Given the results of our study, further study to determine the response of the abnormal joint to allogeneic MSCs should be performed. This is especially important because it has been previously shown that inflammatory stimulation in vitro can induce MSCs to express MHCII, which would enhance the immunogenicity of allogeneic MSCs [50].

A final limitation of this study is that the MHC haplotype and whether AUTO and ALLO pairs were MHCmatched or mismatched is unknown. The study reported here underpins the importance of fully understanding the immunogenicity of allogeneic MSCs intended to be used for intra-articular injection.

\section{Conclusions}

The synovial joint is a unique structure with a distinct blood-joint barrier and different immune makeup of its synovial lining. Understanding the clinical response of the synovial joint to intra-articular injection of allogeneic
MSCs as compared to autologous MSCs is critical prior to use of allogeneic MSCs in clinical patients by intraarticular injection. Herein, we have shown there is minimal reaction to a single or repeated intra-articular injection of autologous MSCs when cells have been FBS depleted, but not allogeneic MSCs, which is in direct contrast to the previous reports in the equine model of a strong adverse reaction after a single injection of autologous or allogeneic MSCs [17, 18]. Our concurrent testing of autologous MSCs with xeno-contaminants from the culture period demonstrate the cause of previously reported profound adverse clinical reaction after autologous and allogeneic MSC intra-articular injection to be intra-cellular xeno-contamination of injected MSCs. The adverse clinical response of increased cellular infiltrate in synovial joints injected with allogeneic MSCs and increased pain and cellular infiltrate in synovial joints injected with MSCs not depleted of FBS is clinically relevant to patient morbidity and may also be relevant to MSC persistence. This is because the cellular infiltrates may indicate an adaptive immune response to the injected MSCs, which may target MSCs for destruction.

\section{Additional files}

Additional file 1: Table S1. Horse number, age in years and group assignments (DOCX $20 \mathrm{~kb}$ )

Additional file 2: Figure S1. FITC-labeled FBS depletion from MSCS (no counterstain, red color is due to background transmitted light resulting in autofluorescence). (A) MSCs prior to the FBS depletion period of 48 hours and (B) and after the FBS depletion period of 48 hours. (C) Histograms of MSCs from each horse in the FBS (top panels) and AUTO groups (bottom panels) after 48 hours of FBS depletion in autologous serum-supplemented culture medium (blue histogram) compared to continued culture in FITC-FBS (green histogram). The gray histogram represents cells not incubated with FITC-labeled FBS. All histograms represent 2000-20,000 cells. (JPG 1595 kb)

Additional file 3: Figure S2. Histogram of MHC Class II expression of MSCs from a (A) representative horse that was negative (horse 10) and (B) horse 2 used for intra-articular injection to the MSC donor (AUTO) and to an allogeneic recipient (horse 14; ALLO). All histograms represent 9000-11,000 cells. (JPG 138 kb)

Additional file 4: Figure S3. Trilineage differentiation of MSCs from a single horse that represents the average result after (A) adipogenic (oil red O), (B) osteogenic (alizarin red) and (C) chondrogenic (toluidine blue) differentiation and the negative controls for (D) adipogenic and (E)

osteogenic differentiation. Cells from all horses successfully underwent trilineage differentiation. Scale bars represent A, C, and D 100 um and B and $\mathrm{E} 500 \mathrm{um}$. (JPG $657 \mathrm{~kb}$ )

Additional file 5: Figure S4. Synovial fluid cytology box plots of total nucleated cell count (TNCC), percentage of neutrophils (PMN), and total protein concentration (TP) for synovial joints injected with control media only (95\% autologous serum, 5\% DMSO and no MSCs). Repeated measures analysis of variance (ANOVA) was used to compare temporal changes in the cytologic outcome variables for each pair of treatment groups (AUTO to FBS and AUTO to ALLO), with horse considered a random effect. These analyses were performed using PROC MIXED, and an autoregressive correlation structure was specified. Treatment group (AUTO, ALLO or FBS), time point, and their interaction were included as factors in the ANOVA. There were no significant differences over time between the groups. (JPG $491 \mathrm{~kb}$ ) 


\section{Abbreviations}

ANOVA: Analysis of variance; DMSO: Dimethyl sulfoxide; FBS: Fetal bovine serum; FITC: Fluorescein isothiocyanate; MHCII: Major histocompatibility complex class II; MSCs: Mesenchymal stem cells; TNCC: Total nucleated cell count; TP: total protein concentration

\section{Acknowledgements}

Not applicable.

\section{Funding}

Funding provided by Link Endowment for Equine Research at Texas A\&M University and the Faculty Grant Program from the Department of Large Animal Sciences at Texas A\&M University.

\section{Availability of data and materials}

All data generated or analyzed during this study are included in this published article.

\section{Authors' contributions}

AJ contributed to collection and assembly of data, data analysis, and final manuscript approval. AM contributed to assembly of data, data analysis, and final manuscript approval. KJC contributed to study design, statistical analysis, and final manuscript approval. CAG contributed to collection and assembly of data, and final manuscript approval. GJL contributed to collection and assembly of data, and final manuscript approval. RS contributed to collection of data, data analysis and interpretation, and final manuscript approval AEW contributed to conception and design, collection and assembly of data, data analysis, manuscript writing, and final manuscript approval. All authors read and approved the final manuscript.

\section{Competing interests}

The authors declare that they have no competing interests.

\section{Consent for publication}

Not applicable.

\section{Ethics approval and consent to participate}

This study was approved by the university's Institutional Animal Care and Use Committee (IACUC protocol number 2013-097). No animals were euthanized for this study.

\section{Author details}

${ }^{1}$ Department of Large Animal Clinical Sciences, Texas A\&M University, College Station, TX 77843, USA. ${ }^{2}$ Department of Veterinary Integrative Biosciences, Texas A\&M University, College Station, TX 77843, USA. ${ }^{3}$ Department of Veterinary Pathobiology, Texas A\&M University, College Station, TX 77843, USA. ${ }^{4}$ Institute for Regenerative Medicine and Department of Molecular and Cellular Medicine, Texas A\&M Health Science Center, Texas A\&M University, Temple, TX 76502, USA.

\section{Received: 23 November 2016 Revised: 30 January 2017} Accepted: 9 February 2017 Published online: 28 February 2017

\section{References}

1. Mcllwraith CW, Frisbie DD, Kawcak CE. The horse as a model of naturally occurring osteoarthritis. Bone Joint Res. 2012;1(11):297-309.

2. Smith RK, Garvican ER, Fortier LA. The current 'state of play' of regenerative medicine in horses: what the horse can tell the human. Regen Med. 2014; 9(5):673-85.

3. Frisbie DD, Trotter GW, Powers BE, Rodkey WG, Steadman JR, Howard RD, Park RD, Mcllwraith CW. Arthroscopic subchondral bone plate microfracture technique augments healing of large chondral defects in the radial carpal bone and medial femoral condyle of horses. Vet Surg. 1999;28(4):242-55.

4. Ferris DJ, Frisbie DD, Kisiday JD, Mcllwraith CW, Hague BA, Major MD, Schneider RK, Zubrod CJ, Kawcak CE, Goodrich LR. Clinical outcome after intra-articular administration of bone marrow-derived mesenchymal stem cells in 33 horses with stifle injury. Vet Surg. 2014;43(3):255-65.

5. Murphy JM, Fink DJ, Hunziker EB, Barry FP. Stem cell therapy in a caprine model of osteoarthritis. Arthritis Rheum. 2003:48(12):3464-74.

6. Soler R, Orozco L, Munar A, Huquet M, Lopez R, Vives J, Coll R, Codinach M, Garcia-Lopez J. Final results of a phase I-II trial using ex vivo expanded autologous mesenchymal stromal cells for the treatment of osteoarthritis of the knee confirming safety and suggesting cartilage regeneration. Knee. 2016;23(4):647-54

7. Orozco L, Munar A, Soler R, Alberca M, Soler F, Huguet M, Sentis J, Sanchez A, Garcia-Sancho J. Treatment of knee osteoarthritis with autologous mesenchymal stem cells: a pilot study. Transplantation. 2013;95(12):1535-41.

8. Jo CH, Lee YG, Shin WH, Kim H, Chai JW, Jeong EC, Kim JE, Shim H, Shin JS, Shin IS, Ra JC, Oh S, Yoon KS. Intra-articular injection of mesenchymal stem cells for the treatment of osteoarthritis of the knee: a proof-of-concept clinical trial. Stem Cells. 2014;32(5):1254-66.

9. Emadedin M, Ghorbani Liastani M, Fazeli R, Mohseni F, Moghadasali R, Mardpour S, Hosseini SE, Niknejadi M, Moeininia F, Aghahossein Fanni A, Baghban Eslaminejhad R, Vosough Dizaji A, Labibzadeh N, Mirazimi Bafghi A, Baharvand H, Aghdami N. Long-term follow-up of intra-articular injection of autologous mesenchymal stem cells in patients with knee, ankle, or hip osteoarthritis. Arch Iran Med. 2015;18(6):336-44.

10. Koh YG, Jo SB, Kwon OR, Suh DS, Lee SW, Park SH, Choi YJ. Mesenchymal stem cell injections improve symptoms of knee osteoarthritis. Arthroscopy. 2013;29(4):748-55.

11. Koh YG, Choi YJ, Kwon SK, Kim YS, Yeo JE. Clinical results and second-look arthroscopic findings after treatment with adipose-derived stem cells for knee osteoarthritis. Knee Surg Sports Traumatol Arthrosc. 2015;23(5):1308-16.

12. Vega A, Martin-Ferrero MA, Del Canto F, Alberca M, Garcia V, Munar A, Orozco L, Soler R, Fuertes JJ, Huguet M, Sanchez A, Garcia-Sancho J. Treatment of knee osteoarthritis with allogeneic bone marrow mesenchymal stem cells: a randomized controlled trial. Transplantation. 2015;99(8):1681-90.

13. Sekiya I, Muneta T, Horie M, Koga H. Arthroscopic transplantation of synovial stem cells improves clinical outcomes in knees with cartilage defects. Clin Orthop Relat Res. 2015;473(7):2316-26.

14. Hourd P, Ginty P, Chandra A, Williams DJ. Manufacturing models permitting roll out/scale out of clinically led autologous cell therapies: regulatory and scientific challenges for comparability. Cytotherapy. 2014;16(8):1033-47.

15. Le Blanc K, Rasmusson I, Sundberg B, Gotherstrom C, Hassan M, Uzunel M, Ringden $\mathrm{O}$. Treatment of severe acute graft-versus-host disease with third party haploidentical mesenchymal stem cells. Lancet. 2004;363(9419):1439-41.

16. Ankrum JA, Ong JF, Karp JM. Mesenchymal stem cells: immune evasive, not immune privileged. Nat Biotechnol. 2014;32(3):252-60.

17. Pigott JH, Ishihara A, Wellman ML, Russell DS, Bertone AL. Investigation of the immune response to autologous, allogeneic, and xenogeneic mesenchymal stem cells after intra-articular injection in horses. Vet Immunol Immunopathol. 2013;156(1-2):99-106.

18. Carrade DD, Owens SD, Galuppo LD, Vidal MA, Ferraro GL, Librach F, Buerchler S, Friedman MS, Walker NJ, Borjesson DL. Clinicopathologic findings following intra-articular injection of autologous and allogeneic placentally derived equine mesenchymal stem cells in horses. Cytotherapy. 2011:13(4):419-30

19. Frisbie DD, McCarthy HE, Archer CW, Barrett MF, Mcllwraith CW. Evaluation of articular cartilage progenitor cells for the repair of articular defects in an equine model. J Bone Joint Surg Am. 2015;97(6):484-93.

20. Hamanishi C. Ultrastructural basis of blood-synovial barrier-results with five electron-opaque tracers. Nihon Geka Hokan. 1978;47(3):259-79.

21. Nishijima T. The fine structure of the synovial membrane of the knee joint in rats with special reference to regional differences. Hihon Seikeigeka Gakkai Zasshi. 1981:55(6):601-13.

22. Iwanaga T, Shikichi M, Kitamura H, Yanase H, Nozawa-Inoue K. Morphology and functional roles of synoviocytes in the joint. Arch Histol Cytol. 2000;63(1):17-31.

23. Spees JL, Gregory CA, Singh H, Tucker HA, Peister A, Lynch PJ, Hsu SC, Smith J, Prockop DJ. Internalized antigens must be removed to prepare hypoimmunogenic mesenchymal stem cells for cell and gene therapy. Mol Ther. 2004;9(5):747-56.

24. Meyer AA, Manktelow A, Johnson M, deSerres S, Herzog S, Peterson HD. Antibody response to xenogeneic proteins in burned patients receiving cultured keratinocyte grafts. J Trauma. 1988;28(7):1054-9.

25. Johnson MC, Meyer AA, deSerres S, Herzog S, Peterson HD. Persistence of fetal bovine serum proteins in human keratinocytes. J Burn Care Rehabil. 1990;11(6):504-9.

26. Mackensen A, Drager R, Schlesier M, Mertelsmann R, Lindemann A. Presence of IgE antibodies to bovine serum albumin in a patient developing anaphylaxis after vaccination with human peptide-pulsed dendritic cells. Cancer Immunol Immunother. 2000;49(3):152-6. 
27. Selvaggi TA, Walker RE, Fleisher TA. Development of antibodies to fetal calf serum with arthus-like reactions in human immunodeficiency virus-infected patients given syngeneic lymphocyte infusions. Blood. 1997;89(3):776-9.

28. Tuschong L, Soenen SL, Blaese RM, Candotti F, Muul LM. Immune response to fetal calf serum by two adenosine deaminase-deficient patients after $T$ cell gene therapy. Hum Gene Ther. 2002;13(13):1605-10.

29. Mendicino M, Bailey AM, Wonnacott K, Puri RK, Bauer SR. MSC-based product characterization for clinical trials: an FDA perspective. Cell Stem Cell. 2014;14(2):141-5.

30. Bieback K, Hecker A, Kocaomer A, Lannert H, Schallmoser K, Strunk D, Kluter H. Human alternatives to fetal bovine serum for the expansion of mesenchymal stromal cells from bone marrow. Stem Cells. 2009;27(9):2331-41.

31. Jung S, Panchalingam KM, Rosenberg L, Behie LA. Ex vivo expansion of human mesenchymal stem cells in defined serum-free media. Stem Cells Int. 2012:2012:123030.

32. Ardanaz N, Vazquez FJ, Romero A, Remacha AR, Barrachina L, Sanz A, Ranera B, Vitoria A, Albareda J, Prades M, Zaragoza P, Martin-Burriel I, Rodellar C. Inflammatory response to the administration of mesenchymal stem cells in an equine experimental model: effect of autologous, and single and repeat doses of pooled allogeneic cells in healthy joints. BMC Vet Res. 2016;12(1):65-77.

33. Mitchell A, Rivas KA, Smith 3rd R, Watts AE. Cryopreservation of equine mesenchymal stem cells in 95\% autologous serum and 5\% DMSO does not alter post-thaw growth or morphology in vitro compared to fetal bovine serum or allogeneic serum at 20 or $95 \%$ and DMSO at 10 or 5 . Stem Cell Res Ther. 2015;6:231-43.

34. Keegan KG, Wilson DA, Wilson DJ, Smith B, Gaughan EM, Pleasant RS, Lillich JD, Kramer J, Howard RD, Bacon-Miller C, Davis EG, May KA, Cheramie HS, Valentino WL, van Harreveld PD. Evaluation of mild lameness in horses trotting on a treadmill by clinicians and interns or residents and correlation of their assessments with kinematic gait analysis. Am J Vet Res. 1998;59(11):1370-7.

35. Keegan KG, MacAllister CG, Wilson DA, Gedon CA, Kramer J, Yonezawa Y, Maki H, Pai PF. Comparison of an inertial sensor system with a stationary force plate for evaluation of horses with bilateral forelimb lameness. Am J Vet Res. 2012;73(3):368-74

36. Ross TN, Kisiday JD, Hess T, Mcllwraith CW. Evaluation of the inflammatory response in experimentally induced synovitis in the horse: a comparison of recombinant equine interleukin 1 beta and lipopolysaccharide. Osteoarthritis Cartilage. 2012;20(12):1583-90

37. Zehr KJ, Herskowitz A, Lee PC, Poston RS, Gillinov AM, Baumgartner WA. Neutrophil adhesion inhibition prolongs survival of cardiac allografts with hyperacute rejection. J Heart Lung Transplant. 1993;12(5):837-44.

38. El-Sawy T, Belperio JA, Strieter RM, Remick DG, Fairchild RL. Inhibition of polymorphonuclear leukocyte-mediated graft damage synergizes with short-term costimulatory blockade to prevent cardiac allograft rejection. Circulation. 2005:112(3):320-31.

39. Grabie N, Hsieh DT, Buono C, Westrich JR, Allen JA, Pang H, Stavrakis G, Lichtman AH. Neutrophils sustain pathogenic CD8+ T cell responses in the heart. Am J Pathol. 2003;163(6):2413-20.

40. Huang XP, Sun Z, Miyagi Y, McDonald Kinkaid H, Zhang L, Weisel RD, Li RK. Differentiation of allogeneic mesenchymal stem cells induces immunogenicity and limits their long-term benefits for myocardial repair. Circulation. 2010;122(23):2419-29.

41. Eliopoulos N, Stagg J, Lejeune L, Pommey S, Galipeau J. Allogeneic marrow stromal cells are immune rejected by MHC class I- and class II-mismatched recipient mice. Blood. 2005;106(13):4057-65.

42. Nauta AJ, Westerhuis G, Kruisselbrink AB, Lurvink EG, Willemze R, Fibbe WE. Donor-derived mesenchymal stem cells are immunogenic in an allogeneic host and stimulate donor graft rejection in a nonmyeloablative setting. Blood. 2006;108(6):2114-20.

43. Isakova IA, Dufour J, Lanclos C, Bruhn J, Phinney DG. Cell-dose-dependent increases in circulating levels of immune effector cells in rhesus macaques following intracranial injection of allogeneic MSCs. Exp Hematol. 2010; 38(10):957-67

44. Hare JM, Fishman JE, Gerstenblith G, DiFede Velazquez DL, Zambrano JP, Suncion W, Tracy M, Ghersin E, Johnston PV, Brinker JA, Breton E, DavisSproul J, Schulman IH, Byrnes J, Mendizabal AM, Lowery MH, Rouy D, Altman P, Wong Po Foo C, Ruiz P, Amador A, Da Silva J, McNiece IK, Heldman AW, George R, Lardo A. Comparison of allogeneic vs autologous bone marrow-derived mesenchymal stem cells delivered by transendocardial injection in patients with ischemic cardiomyopathy: the POSEIDON randomized trial. JAMA. 2012;308(22):2369-79.
45. Camp DM, Loeffler DA, Farrah DM, Borneman JN, LeWitt PA. Cellular immune response to intrastriatally implanted allogeneic bone marrow stromal cells in a rat model of Parkinson's disease. J Neuroinflammation. 2009:6:17-2094-6-17.

46. Poncelet AJ, Vercruysse J, Saliez A, Gianello P. Although pig allogeneic mesenchymal stem cells are not immunogenic in vitro, intracardiac injection elicits an immune response in vivo. Transplantation. 2007;83(6):783-90.

47. Badillo AT, Beggs KJ, Javazon EH, Tebbets JC, Flake AW. Murine bone marrow stromal progenitor cells elicit an in vivo cellular and humoral alloimmune response. Biol Blood Marrow Transplant. 2007;13(4):412-22.

48. Berglund AK, Schnabel LV. Allogeneic MHC-mismatched equine bone marrow-derived mesenchymal stem cells are targeted for death by cytotoxic anti-MHC antibodies. Equine Vet J. 2016. doi: 10.1111/evj.12647

49. Pezzanite LM, Fortier LA, Antczak DF, Cassano JM, Brosnahan MM, Miller D, Schnabel LV. Equine allogeneic bone marrow-derived mesenchymal stromal cells elicit antibody responses in vivo. Stem Cell Res Ther. 2015;6:54.

50. Schnabel LV, Pezzanite LM, Antczak DF, Felippe MJ, Fortier LA. Equine bone marrow-derived mesenchymal stromal cells are heterogeneous in $\mathrm{MHC}$ class $\|$ expression and capable of inciting an immune response in vitro. Stem Cell Res Ther. 2014;5(1):13.

51. Petroff MG. Review: Fetal antigens-identity, origins, and influences on the maternal immune system. Placenta. 2011:32 Suppl 2:S176-81.

52. Gregory CA, Reyes E, Whitney MJ, Spees JL. Enhanced engraftment of mesenchymal stem cells in a cutaneous wound model by culture in allogenic species-specific serum and administration in fibrin constructs. Stem Cells. 2006:24(10):2232-43.

53. Williams LB, Koenig JB, Black B, Gibson TW, Sharif S, Koch TG. Equine allogeneic umbilical cord blood derived mesenchymal stromal cells reduce synovial fluid nucleated cell count and induce mild self-limiting inflammation when evaluated in an LPS induced synovitis model. Equine Vet J. 2015;48(5):619-25.

54. Prockop DJ, Prockop SE, Bertoncello I. Are clinical trials with mesenchymal stem/progenitor cells (MSCs) too far ahead of the science? Lessons from experimental hematology. Stem Cells. 2014;32(12):3055-61.

55. Ginis I, Grinblat B, Shirvan MH. Evaluation of bone marrow-derived mesenchymal stem cells after cryopreservation and hypothermic storage in clinically safe medium. Tissue Eng Part C Methods. 2012;18(6):453-63.

56. Moll G, Alm JJ, Davies LC, von Bahr L, Heldring N, Stenbeck-Funke L, Hamad OA, Hinsch R, Ignatowicz L, Locke M, Lonnies H, Lambris JD, Teramura $Y$, Nilsson-Ekdahl K, Nilsson B, Le Blanc K. Do cryopreserved mesenchymal stromal cells display impaired immunomodulatory and therapeutic properties? Stem Cells. 2014;32(9):2430-42.

57. Moses VS, Hardy J, Bertone AL, Weisbrode SE. Effects of anti-inflammatory drugs on lipopolysaccharide-challenged and -unchallenged equine synovial explants. Am J Vet Res. 2001;62(1):54-60.

58. Hraha TH, Doremus KM, Mcllwraith CW, Frisbie DD. Autologous conditioned serum: the comparative cytokine profiles of two commercial methods (IRAP and IRAP II) using equine blood. Equine Vet J. 2011:43(5):516-21.

59. Ekman L, Nilsson G, Persson L, Lumsden JH. Volume of the synovia in certain joint cavities in the horse. Acta Vet Scand. 1981;22(1):23-31.

60. Peters AE, Watts AE. Biopsy needle advancement during bone marrow aspiration increases mesenchymal stem cell concentration. Front Vet Sci. 2016;3:23.

\section{Submit your next manuscript to BioMed Central and we will help you at every step:}

- We accept pre-submission inquiries

- Our selector tool helps you to find the most relevant journal

- We provide round the clock customer support

- Convenient online submission

- Thorough peer review

- Inclusion in PubMed and all major indexing services

- Maximum visibility for your research

Submit your manuscript at www.biomedcentral.com/submit 